\title{
Tackling Negative Representation: The Use of Storytelling As a Critical Pedagogical Tool for Positive Representation of Roma
}

\section{Georgia Kalpazidou}

gkalpazi@gmail.com

Aristotle University of Thessaloniki, Greece

ORCID: https://orcid.org/0000-0003-3671-1018

Georgia Kalpazidou is a Greek philologist and a postgraduate student of Historical and Balkan Linguistics at Aristotle University in Thessaloniki. Her Romani origins prompted her to specialize in Romani Linguistics. She has worked as an educator and cultural mediator. Since 2019 she is assistant researcher in the project Areal Typology with Emphasis on Balkan Data of the Institute of Modern Greek Studies. She is a member of Alternative Innovative Development (AID).

\section{Dimitris Alexandros Ladopoulos}

dimlado@hotmail.com

Alternative Innovative Development, Larisa, Greece

ORCID: https://orcid.org/0000-0002-5301-3767

Dimitrios Alexandros Ladopoulos, co-founder and member of Alternative Innovative Development, studied Rural and Survey Engineering. He has supervised several projects in multiple management and administrative roles. His main topics of interest are new technologies, adult education through non-formal learning methods, environment, and youth entrepreneurship, with a special focus on vulnerable groups.

\section{Theofano Papakonstantinou}

feniapapakonstantinou@gmail.com

Aristotle University of Thessaloniki, Greece

Alternative Innovative Development, Thessaloniki, Greece

ORCID: https://orcid.org/0000-0001-8190-2142

Theofano Papakonstantinou, co-founder of Alternative Innovative Development, is a $\mathrm{PhD}$ candidate at Aristotle University of Thessaloniki in the School of Early Childhood Education, Faculty of Education. She was a member of the Advisory Council on Youth of the Council of Europe from 2017 to 2019. Among her multiple interests are adult education, non-formal learning methods, entrepreneurship, and the implementation of innovative action plans with an emphasis on supporting Roma and other vulnerable social groups. 


\section{Abstract}

This article focuses on the negative representation of Roma in Greece in the early twenty-first century. It investigates how negative feedback takes the form of a self-fulfilling prophecy that suppresses the self-esteem of young Roma and maintains a distance between Romani identity and education despite several positive yet little known examples of Romani scientists and scholars. The article questions how negative Romani images can be reversed in order to enhance Roma's educational success. The importance of innovative educational activities based on Romani literature, critical multiculturalism, and the parameter of Romani bilingualism is highlighted. Particularly, the article focuses on the power and the echo that stories can have (storytelling), where protagonists have a Romani connection or identity and are portrayed as positive models, both within classrooms with Romani students and within a society where the idea of Romani literature is a fantasy.

\section{Keywords}

- Critical pedagogy

- Multiculturalism

- Romani representation

- Self-fulfilling prophecy

- $\quad$ Storytelling 


\section{Introduction: In the Spectrum of Negative Representation}

It is estimated that Roma and Travellers, with a population of more than 10 million, constitute the largest minority group in Europe and face day-to-day discrimination and marginalization. The vast majority of European citizens hold established views about the contemporary social representation of Roma, even if these views are not based on personal experience (Matras 2013). As Matras mentions, "No tabula rasa is available when it comes to briefing politicians, media, or the wider public about Roma/Gypsies and their needs or aspirations" $(2013,2)$. This viewpoint is most likely to be negative, as depicted in Google's imagery for searches of the word "Roma."

Negative beliefs easily lead to harmful outcomes, both for individuals who directly are affected by stereotypes and for society at large (Maučec 2013), especially when popular media representation of misunderstood groups in the digital era can feed fear and paranoia and exacerbate community conflict (Richardson 2014). As Richardson mentions, "anti-Gypsy discourse is hegemonic and can constrain groups' freedom to practice individual cultures through heightening their 'otherness' and therefore subjecting them to increased social surveillance and control" $(2014,51)$.

Focusing on the depiction of Roma in Greece, the above portrait persists. Riga and Demonakou observe that " $\mathrm{t}]$ he issue of the meeting of the cultural identities of the Greeks and Roma in Greece, seen through the prism of their conflicting relationship in daily practice, is 'burdened' by the hue of cultural diversity that the identity of the latter carries within it" (Riga and Demonakou 2002, 280).

Biased representations towards Roma are unfortunately common phenomena within and outside the borders of Greece. Roma are considered to be parasitical elements in a territory where they have been present for centuries. Undoubtedly, one-sided social coverage of Roma perpetuates inequalities and builds higher walls among Greek Roma and Greek non-Roma in a relatively small country, defying the fact that these two groups often share a common reality with common problems, which usually stems from the state's inability to take care of vulnerable groups. In the end, as Maučec describes, "Despite some positive stereotypes (e.g. Roma have a natural talent for music), the stereotypes about Roma are overwhelmingly negative" $(2013,184)$.

Negative viewpoints link to negative expectations. Interpersonal expectations are powerful (Madon, Jussim, and Eccles 1997) and date back to Merton's (1948) coining of the term self-fulfilling prophecy, which is defined as "a false definition of the situation evoking a new behavior which makes the originally false conception come true" $(1948,195)$. According to Merton (1948), the common pattern of the selffulfilling prophecy explains a host of social problems such as discrimination against stigmatized groups. By way of explanation, the term refers to initially false beliefs that lead the "victim" to act similarly and to correspond to negative expectations which are especially powerful among certain targets (Madon, Jussim, and Eccles 1997). 
A false belief that persists in the early twenty-first century is that Roma are unable to learn and that their culture is incompatible with education. Poor school attendance by Romani students usually is connected to Romani identity by non-Romani people (Moucheli 1996; Komis 1998; Gotovos 2004b in Nikolaou 2009) who ignore a number of serious socio-economic causes. The academic success of Romani students comes as a shock to many, and this attitude can be confirmed by the author's personal experience: when she entered university in 2007, a newspaper article was published with the headline "A 19-year-old Gypsy Girl Breaks the Stereotypes" (Macedonia 2008).

Social beliefs are so ingrained that even young children are surprised that a Romani man or woman has attended university, underlining the pervasiveness and strength of this self-fulfilling prophecy that suppresses the self-esteem of young Roma. This is especially poignant when Romani students learn from a Romani teacher in the classroom. From the author's personal and professional observations, elementary school students persistently were unable to understand how Romani women study in university, since "Romani women do not study." Even if a growing number of Romani scientists are noted contributors to their respective fields around the world, they usually are invisible among Romani societies. ${ }^{[1]}$

Moreover, educational systems and educators are affected deeply by the stereotype of "natural" Romani disaffection (Flecha and Soler 2013), and this situation is reflected in the curriculum and way of teaching (Kokkoni 2017). Teachers aim to bring students into conformity with the dominant culture and the values and behaviors of the majority (Kokkoni 2017), thus rejecting the identity of students from minority groups, such as Roma, who come from different socio-linguistic backgrounds. Kyuchukov writes, "Teachers expect Roma children to know how to cope with the school rules" $(2000,274)$. But whenever this expectation is not met, the student-teacher relationship is impacted, often negatively.

Schools as institutions represent a particular and dominant system of values and a particular language that together may operate to marginalize those students who deviate from them. In other words, a monolingual and monocultural orientation causes a fear of noncompliance and exclusion, which piles pressure on children, followed by feelings of inferiority (Kokkoni 2017). Thus, a combination of negative experiences, an unfamiliar school environment, and the influence of teachers' negative attitudes often leads students to leave school early (Kokkoni 2017).

How can Roma and especially Romani students escape this vicious cycle of reproduction of a negative representation of Romani identity and culture in schools and society at large? First, this article aims to highlight the importance of designing, organizing, and implementing multicultural educational activities for elementary and high school pupils, using the methodological approach of oral storytelling as a critical and multicultural pedagogical tool and learning method. It also sheds light on the need to enhance the depth of pupils' cultural experiences and identity by exposing them to the idea of Romani literature and by developing their critical abilities as strategies to navigate the trap of Romani self-fulfilling prophecies in education.

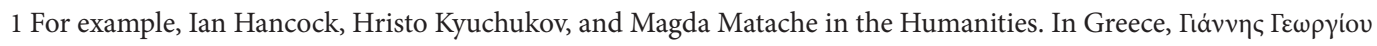






\section{Multiple Reforms of Education Now}

In today's Greek school environment, students from different linguistic and cultural backgrounds may not have sufficient stimuli to help them to adapt to the reality of school. Due to a lack of appropriate teaching methods to help them cope, they underperform in school, have negative perceptions about school, or even experience outright rejection. The low rate of attendance of Romani students in Greece is confirmed in research by the European Union Agency for Fundamental Rights (2014) in which 43 percent of Romani children of compulsory school-age are reported to be not attending school. This percentage is one of the two highest rates in Europe of Romani children not attending compulsory education.

In particular, regarding the education of Romani children, Liegeois (1999) states that schools have paid little attention to the way Roma educate their children within the family, while pedagogical school practices seem contradictory, resulting in divisive positions. Vasileiadou and Pavli-Korre (2011) emphasize that today's schools reject Romani children, their skills, culture, and language, with the result that Romani children experience the conflict of two different value systems, that of the school and that of the community. In fact, Vasileiadou and Pavli-Korre (2011) underline that the introduction of intercultural thematic units is insufficient, and a modernization of teaching methods is required.

Although progress has been made in recent years in reducing the school dropout rate of Romani children, the rates of Romani children's nonattendance of school in relation to the general population continue to be high, which is in line with an outstanding need to revise both educational protocols and thematic methods and teaching methods of the schools.

An educational system is like a vivid organism; it must be able to change, evolve, and adapt according to historical and social contexts (Chartier 1991). In a multicultural society, education has to be multicultural, too, in order to be sustainable and efficient.

Banks and Banks (2010) highlight the tripartite composition of multiculturalism which consists of the concept, the educational reform movement, and the process. In a multicultural frame, where differences are equalized, social asymmetries and variables are perceived not as difficulties but as positive contributions (Kellner 2003, 96).

In conjunction, multicultural education is a broad concept with several different and important dimensions and should be viewed as an ongoing process (Banks 2004). Practicing educators can use the dimensions as a guide to school reform when trying to implement multicultural disciplines in the way of teaching. The dimensions include content integration, the knowledge construction process, prejudice reduction, equity pedagogy, and an empowering school culture and social structure (Banks and Banks 2010).

In fact, critical pedagogy and multicultural education complement each other; when merged, they become an attitude or ideology that helps teachers "to confront and engage the world critically and challenge power relations" (Sleeter and McLaren 1995, 7). Chan (2011) highlights that critical pedagogy 
is grounded in social justice and equality. Banks and Wink also support the idea that critical teachers need to realize that education is a political site for power struggles and that the educational curriculum is a political document (Banks 2004; Wink 2005).

Multicultural education should focus on the development of healthy identities and of intergroup awareness, through teaching about cultural practices without stereotyping or misinterpreting (Banks and Banks 2010). A way that could lead students to experience multiculturalism is storytelling (Chartier 1991), which is aligned closely with non-formal education.

Non-formal education may be aimed at people who do not have access to formal education or cannot complete the full cycle of basic education (Yasunaga 2014). Non-formal education has significant advantages as it can be adapted to the specific learning needs of individuals and populations in different conditions. The resilience of non-formal education and environmentally friendly approaches are appropriate and useful for fulfilling the right to education of marginalized groups and populations with special learning needs.

Additionally, multiculturalism is linked to multilingualism. Despite multilingualism surrounding us, monolingualism still prevails. In previous decades the bilingualism of minorities was perceived as a deficiency and was correlated to low scores and school failure (Oller and Eilers 2002). However, planning actions within the framework of intercultural education principles and encouraging the use of minority languages can lead to enhancing positive language attitudes as well as allowing students to redefine their identities and to strengthen their self-esteem. As Kokkoni mentions "bilingualism should not be degraded nor its speakers" $(2017,99)$.

Concerning Romani bilingualism, this parameter usually is ignored. Nonetheless, "When the majority (finally) starts to appreciate the Romani language and Romani bilingualism in all its richness then a transformation of society will take place" (Kyuchukov 2000, 278). This article supports the view that the use of narratives which include elements of Romani life and give the chance to students to express themselves in Romani could work in the above-mentioned direction.

\section{The Dendropotamos Case Study}

Since 2013, the author has participated in interventions in local schools in Dendropotamos, a Romani district close to Thessaloniki's city center, as a teacher and cultural mediator under the Education of Roma Children Program of the Pedagogy Faculty of the Aristotle University of Thessaloniki. During her interactions with Romani high school students, the author noticed that many Romani students expressed a passive and unmotivated attitude towards school, which is unsurprising as school represents a foreign and distant place where negative representations of Roma persist.

Disappointingly, even if a Romani student expresses a willingness for more active engagement and learning, the school often is unable to play a more supportive role. Romani adolescents, and especially teenage girls, have to face not only discrimination from mainstream society but also the frequently negative reactions of 
their family members if they show a preference to study and follow an academic/professional career rather than marrying, which is the first choice expected of a Rom/Romni in their community. Exactly here at this life juncture does the self-fulfilling prophecy begin to come true. To overcome such personal barriers, young Roma have to summon the courage to make decisions against the norm, particularly when their choices are treated with irony and contemptuous attitudes within close-knit family environments. As a result, it is reasonable for students who have no "ally" to give up far too soon.

Given the fact that schools usually do not stray from their typical teaching program and tend to ignore the individual needs of students, it is easy to understand why school seems unattractive to those students with particular cultural characteristics.

The purpose of the researcher's interventions was to interact with Romani students and to devise a way that regular school attendance might be integrated into Romani culture. Materials for the interventions were to be based on Romani students' living conditions in order to connect two seemingly incompatible concepts: school and Romani culture.

The Dendropotamos case study aimed to examine whether and to what extent the method of storytelling - both as a critical pedagogical tool and as a made-up story where the protagonist was a positive Romani character - could contribute to tackling the negative representation of Roma. It also aimed to measure how storytelling could promote the active participation of students in the classroom and enhance their cultural background and identity by recognizing and utilizing elements of their culture in an unfamiliar school context.

Storytelling workshops took place at Dendropotamos high school in 2018 over four teaching hours and were held for approximately 20 bilingual Arli Romani freshman with low educational levels and low socioeconomic backgrounds. The students were separated into two groups of ten. Participatory observation formed the core of the methodology and extensive notes were taken before and after the workshops in order to observe the reactions, attitudes, and comments of participating students.

Mixing storytelling and non-formal education has been gaining acceptance globally as an important empowerment tool. Narrative is a widely used educational strategy and common in Greece, especially fairy tales that create a pleasant and creative learning environment. It should be noted that oral narration is highly regarded in Romani culture. Consequently, this study also aimed to outline the use of storytelling and the art of narration for the purpose of a positive representation of Roma.

Numerous scholars support the pedagogical value of storytelling. For instance, Burk (2000) proposes the use of storytelling for at-risk students. In her paper, it is suggested that implementing storytelling as a pedagogical tool helps to cultivate an empowering learning environment and to demonstrate cultural pride and confidence (Burk 2000, 7). Furthermore, Akbar mentions that "storytelling is one of the learning methods to practice critical thinking" (Dewey 1910 cited in Akbar 2018, 2), also referring to investigations and analyses about the use of the storytelling process in enhancing critical thinking skills. Conjointly, fairy tales are tools "by which we close the gap between the sensorial input and the abstract concept" (Hohr 2000, 96). 
In the context of intercultural intervention, the researcher authored a story entitled "Butterfly Irene and the Magic Recipe" in which the protagonist has Romani origins, and her magic recipe - asking for and gathering knowledge - helps her to develop herself and to travel around the world. The story represents Roma positively, an uncommon feature of most Romani characters in literature, and it was the researcher's main tool to assess the issue of representation of Roma and their relationship to education.

The researcher read the story aloud and then asked students to express their opinion about the story and Irene's recipe, which lead to lifelong learning. The issue of education in relation to Romani daily life was the central topic. The researcher asked students questions such as what Irene's goal was, how did she achieve it, and if it was truly a "problem" that she had Romani origins, with the goal to provoke critical thinking.

Additionally, in order to be given the impetus for a critical look of the world beyond the borders of their neighborhood, students were asked to think and write their questions about the world, as Butterfly Irene had, provoking an interesting discussion among the students.

The basic purpose of the story was to deliver a symbolic message that education is perhaps the only way to achieve a better life, that education allows us to grow wings, no matter if we are from Romani or nonRomani origins. Knowledge and education are considered the recipe for transforming our view about ourselves and others' views about us, keeping in mind that education is not a privilege but a human right.

An underlying purpose of this intervention was to draw students' attention to the fact that Romani origins do not automatically block us from education and from any kind of literacy. Tellingly, Romani literature is completely absent from school and educational horizons in Greece. Roma appear in literature only as ethnographic characters imbued with mostly negative stereotypical features. So far, there is no interest in Romani writers and their literature production. As a result, Romani students are not looking for Romani literature as they are unaware of its existence and consider themselves excluded from this area of arts and culture.

\section{Results}

Before the intervention, the researcher and students held a discussion. Some students mentioned that they attend school because they have nowhere else to go when their parents are working or only because they have fun with their friends at school. The researcher observed that there was a feeling of distance among students from the goals represented by the institution of their school. In other words, youngsters assumed that they would get married in a few years, so attending school was not that important.

After the narration of the story, students were pleasantly surprised; they were not used to a positive representation of Roma, especially in literary contexts. Thereafter, an interactive conversation started about the benefits of education and about students' problems and difficulties with school attendance as well as their future dreams. After some encouragement, children expressed themselves verbally in Greek 
and in Romani, their mother tongue, and they were happy that they could use their language at school. More students were more actively engaged to participate in the discussion when allowed to speak their mother tongue.

The researcher and pupils shared their common worries, and the researcher, in an attempt to inspire them, shared with them her personal story about how she managed to overcome the obstacles that arise due to Romani culture such as early marriages in addition to the underestimated socio-linguistic status of Roma. Students then began to talk about various professions in which they were interested. Some girls said that they wanted to become like Butterfly Irene or like the Romani teacher with them in the classroom.

The children, in cooperation with an art teacher, illustrated the story within a month, and they presented their work to the school. During the presentation, teachers positively observed that the children were excited. Moreover, students added their own questions such as where Zulus live, who built Thessaloniki's White Tower, or when Christopher Columbus was born, which were answered by teachers; they also referred to their dreams and future professional plans.

Moreover, the fact that they saw a member of their community in the role of a teacher - in a role that so far was "opposite" of the image of Roma and mostly was connected to gadje - created the impression that Romani origins are not an obstacle to achieving personal goals and improving one's life. Moreover, many Romani students opined that if someone, and especially a woman, from their community has managed to go to university and become a teacher, then they could do the same.

A combination of storytelling and interactive dialogue proved to be an excellent student learning tool for the adoption of values and creating opinions. By fostering student engagement, the researcher and students shared their cultural knowledge and offered different and alternative perspectives not widely disseminated in society. By sharing the storytelling processes and taking turns, the researcher offered the "floor" to pupils and structured a classroom talk that allowed and facilitated discussion. By linking themes and scaffolding learning, students engaged in an interactive environment that related theoretical constructs with practical experience and problem-solving skills.

It is worth mentioning that the above action resounded beyond the context of the school environment. Its echo reached the wider social environment of the children as they excitedly conveyed this unexpected school experience. Students' parents reacted positively in their comments to the researcher.

Positive school experiences that allow for the dismantling of students' stigmatized identities have a wider positive impact on students' families and contribute to a different, critical way of thinking based on a multicultural view. When parents feel that their children are not pushed to the sidelines and that their culture receives respect in an unfamiliar environment like school, it becomes easier for parents to support their children's education. Thus, their school, the school of gadje, became our school, too.

In sum, these activities cultivated free expression, communication, imagination, and inspiration, leading to a positive and effective enhancement of Romani students' cultural identity, along with the culture of different social groups. Additionally, it should be emphasized that the Romani community 
of Dendropotamos, like many others, is unfamiliar with Romani literature and the idea of literature production by Roma. Contact with modern literary texts written by and for Roma can serve as a starting point for familiarizing students with contemporary Romani writing. Such contact may serve as a fertile ground for developing a different approach towards the representation of Romani identity, by both Romani and non-Romani individuals.

\section{Conclusion}

The negative social representation of Roma is a phenomenon with deep roots that date back centuries. Yet the need to tackle anti-Romani attitudes is absolutely necessary in order to maintain if not increase social cohesion. School has a significant role in mitigating the negative representation of Roma within Romani communities as well as wider society by transforming difficulties into possibilities.

Furthermore, values and self-perception are inextricably linked to frames of references (Mezirow 1997). Therefore, if members of stigmatized groups, subconsciously or not, believe that their personal development is bounded by their racial identity and not by their personal goals, it is necessary to revise their views, in order to take firm control of their lives and to make decisions that will be based on their own personal needs and not on stereotypes.

The development of critical thinking assumes the formation of individual identity, which is one of the targets of transformative learning, and critical thinking also strengthens an individual's emancipation from foreign but taken-for-granted assumptions (Cranton 2000). Here, teachers have a duty to contribute to this development process. As this articles suggests, oral storytelling can be used as a tool to work with Romani children; storytelling and including positive Romani life stories can play an important role for alternative interpretations of reality, especially during childhood so as to empower Romani students to fight against the trap of a self-fulfilling prophecy of school failure. Storytelling and subsequent teacher-student interactions provide meaning within the learning process, ranging from practical experiences to theoretical constructs.

Non-formal activities that are unpopular in the traditional teaching methods of many schools appear to be a valuable tool for Romani students. Establishing learning environments that allow students to express themselves in their mother tongue gives a positive impulse to students, respecting them for their culture and language, and integrating them into the wider social context. Ultimately, this article confirmed that narration was an important learning tool, where students, through tales and stories, were engaged in how to be inquisitive about the knowledge being disseminated.

A school that uses teaching methods designed to inspire Romani students and that embraces the life experiences and stories of Roma is a positive example that should be explored further. Collecting a larger, more representative sample (different areas, different ages) over a longer observation period may lead to a deeper understanding applicable to the wider school system in Greece.

The limitations of this study need to be considered when interpreting these findings. First, the researcher's own sensitivity and integrity were the primary instruments of data collection and analysis. 
However, neither is training readily available to aspiring case study researchers nor are there guidelines in constructing the final report.

Second, time limitations hampered the effort to examine the phenomena in depth. Further limitations involve issues of reliability, validity, and generalizability (Hamel 1993), or as Guba and Lincoln (1981) refer, the "unusual problems of ethics" since an unethical researcher and author could select specific data to lead to concrete results that they wish to be illustrated. A lack of representativeness and rigor in collection, construction, and analysis need to be mentioned. Future research requires the collection of more variables in a more representative sample (different areas, different ages) over a longer observation period that can lead to better understanding and conclusions.

\section{Acknowledgments}

I would like to express my gratitude to the two co-authors of this article, Dimitris Alexandros Ladopoulos and Theofano Papakonstantinou, from the nongovernmental organization Alternative Innovative Development (AID) for their help, support, and encouragement. They were great colleagues in my first academic steps. I also would like to thank professor Hristo Kyuchukov for his constructive comments. 


\section{References}

Akbar, Taufic. 2018. Analyzing the Emergence of EFL Students Critical Thinking and Critical Literacy Ability in Story Telling Project. Doctoral Dissertation, UIN Sunan Gunung Djati Bandung.

Banks, James A. 2004. “Teaching for Social Justice, Diversity, and Citizenship in a Global World.” The Educational Forum 68 (4): 296-305. https://doi.org/10.1080/00131720408984645

Banks, James A., and Cherry A. M. Banks, eds. 2010. Multicultural Education: Issues and Perspectives, $7^{\text {th }}$ Edition. London: Wiley.

Burk, Nanci M. 2000. Empowering At-risk Students: Storytelling As a Pedagogical Tool. Paper presented at the annual meeting of the National Communication Association, Seattle, WA.

Chan, Angel. 2011. "Critical Multiculturalism: Supporting Early Childhood Teachers to Work with Diverse Immigrant Families." International Research in Early Childhood Education 2 (1): 63-75.

Chartier, Mary K. 1991. "Multicultural Literature through the Magic of Storytelling." Theses Digitization Project. 737. https://scholarworks.lib.csusb.edu/etd-project/737

Cranton, Patricia. 2000. "Individual Differences and Transformative Learning." In Learning As Transformation: Critical Perspectives on a Theory in Progress, edited by Jack Mezirow, 181-204. San Francisco: Jossey-Bass.

Cummins, Jim. 2000. Language, Power and Pedagogy: Bilingual Children in the Crossfire, Vol. 23. Toronto: Multilingual Matters. https://doi.org/10.21832/9781853596773

European Union Agency for Fundamental Rights. 2014. Violence against Women: An EU-wide Survey: Main Results. Vienna: European Union Agency for Fundamental Rights.

Flecha, Ramón, and Marta Soler. 2013. “Turning Difficulties into Possibilities: Engaging Roma Families and Students in School through Dialogic Learning." Cambridge Journal of Education 43 (4): 451-465. https://doi.org/10.1080/0305764x.2013.819068

Guba, Egon, and Yvonna Lincoln. 1981. Effective Evaluation. San Francisco: Jossey-Bass.

Hamel, Jacques. 1993. Case Study Methods. Qualitative Research Methods, Vol. 32. Thousand Oaks, CA: Sage.

Hohr, Hansjörg. 2000. Dynamic Aspects of Fairy Tales: Social and Emotional Competence through Fairy Tales. Scandinavian Journal of Educational Research 44 (1): 89-103. https://doi.org/10.1080/713696665

Kellner, Douglas. 2003. Media Culture: Cultural Studies, Identity and Politics between the Modern and the Postmodern. London: Routledge.

Kready, Laura F. 1916. A Study of Fairy Tales. New York: Houghton Mifflin.

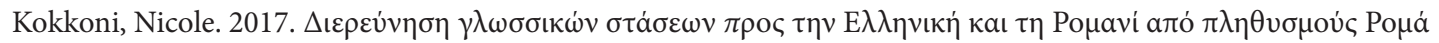

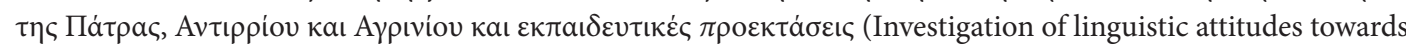
Greek and Romani by the Roma populations of Patras, Antirrio and Agrinio and educational extensions). Doctoral Dissertation. University of Patras.

Kyuchukov, Hristo. 2000. “Transformative Education for Roma (Gypsy) Children: An Insider's View.” Intercultural Education 11 (3): 273-280. https://doi.org/10.1080/14675980020002420

Luke, Allan. 1997. Critical Approaches to Literacy. In Encyclopedia of Language and Education, 143-151. Dordrecht: Springer.

Liégeois, Jean-Pierre. 1999. Roma, Tsigganoi, Taxideutes (Roma, Gypsies, Travellers). Athens: Kastaniotis. 
Madon, Stephanie, Lee Jussim, and Jacquelynne Eccles. 1997. "In Search of the Powerful Self-fulfilling Prophecy." Journal of Personality and Social Psychology 72 (4): 791. https://doi.org/10.1037/0022-3514.72.4.791

Matras, Yaron. 2013. "Scholarship and the Politics of Romani Identity: Strategic and Conceptual Issues." European Yearbook of Minority Issues Online 10 (1): 209-247. https://doi.org/10.1163/22116117-01001010

Maučec, Gregor. 2013. "Identifying and Changing Stereotypes between Roma and non-Roma: From Theory to Practice." Innovative Issues and Approaches in Social Sciences 6 (3): 181-202.

https://doi.org/10.12959/issn.1855-0541.iiass-2013-no3-art10

Merton, Robert K. 1948. “The Self-fulfilling Prophecy." The Antioch Review 8 (2): 193-210. https://doi. org/10.2307/4609267

Mezirow, Jack. 1997. “Transformative Learning: Theory to Practice." New Directions for Adult and Continuing Education 74: 5-12. https://doi.org/10.1002/ace.7401

Napier, Jemina. 2010. "A Case Study of the Use of Storytelling As a Pedagogical Tool for Teaching Interpreting Students." The Interpreter and Translator Trainer 4 (1): 1-32. https://doi.org/10.1080/1750399x.2010.10798795

Nikolaou, Georgios. 2009. “Teacher Training on Roma Education in Greece: A Discussion about the Tesults of INSETRom Experience in Two Greek schools. Intercultural Education 20 (6): 549-557. https://doi.org/10.1080/14675980903448585

Oller, Kimbrough, and Rebecca Eilers, eds. 2002. Language and Literacy in Bilingual Children Vol. 2. Toronto: Multilingual Matters. https://doi.org/10.21832/9781853595721



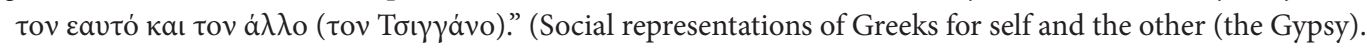

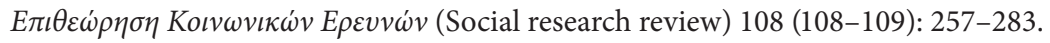
https://doi.org/10.12681/grsr.9072

Sleeter, Christine. E., and Peter McLaren, eds. 1995. Multicultural Education, Critical Pedagogy, and the Politics of Difference. Albany: SUNY Press.

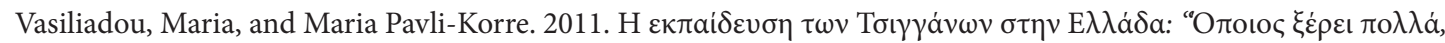


$\Delta$ I.BI.M.

White, Robert E., and Karyn Cooper. 2015. "What Is Critical Literacy?” In Democracy and Its Discontents. Cultural Pluralism Democracy, Socio-Environmental Justice \& Education. Rotterdam: Sense Publishers. https://doi.org/10.1007/978-94-6300-106-9_2

Wink, Joan. 2005. Critical Pedagogy: Notes from the Real World. New York: Pearson/Allyn and Bacon.

Yasunaga, Mari. 2014. "Non-formal Education As a Means to Meet Learning Needs of Out-of-school Children and Adolescents." Background Paper prepared for Fixing the Broken Promise of Education for All: Findings from the Global Initiative on Out-of-School Children. Montreal: UNESCO Institute for Statistics.

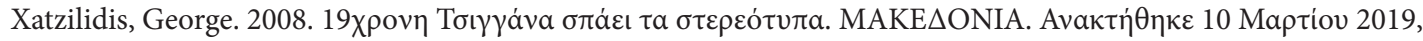
ađó: https://www.makthes.gr/19chroni-tsiggana-spaei-ta-stereotypa-15379 